JOURNAL Of

CONTEMPORARY INDONESIAN ART

Jurusan Seni Murni

FSR ISI Yogyakarta

ISSN: 2442-3394

E-ISSN: $2442-3637$

\title{
REPRESENTASI SIMBOLIS OBJEK-OBJEK MINIATUR DALAM LUKISAN
}

\author{
Oleh: Amin Batoory \\ Institut Seni Indonesia Yogyakarta
}

\begin{abstract}
ABSTRAK
Karya seni merupakan salah satu media untuk berekspresi serta kemampuan kreatif manusia dalam menanggapi pengalaman hidupnya. Pengalaman hidup, pandangan-pandangan dan ekspresi yang muncul menjadi ide dan gagasan yang kemudian diolah menjadi simbol-simbol dan metafora, diwujudkan menjadi sebuah karya seni. Penciptaan karya muncul karena adanya ketertarikan terhadap keindahan sejarah dan budaya serta keinginan untuk memberikan informasi yang lebih luas tentang kebudayaan Timur Tengah dan sejarah Afghanistan. Afghanistan yang dilanda perang berkepanjangan pernah menjadi bagian pusat peradaban kuno karena letaknya di jalur sutra. Lubang kosong tempat dimana patung Buddha raksasa di Bamiyan berdiri merupakan saksi bisu peradaban yang diterpa perang berkepanjangan. Ketidaktahuan akan sejarah menghasilkan sebuah perilaku yang fatal. Penyangkalan sejarah berarti penyangkalan identitas suatu wilayah sehingga sebuah bangsa merasa tidak memiliki akar dan merasa kerdil. Proses mengekspresikan gagasan kedalam wujud karya lukis diwujudkan dengan karakter-karakter miniatur dan artefak-artefak dari Afghanistan yang diadaptasi dimana tiap figur menceritakan ceritanya sendiri sebagai bagian dari narasi yang kompleks. Cerita-cerita yang dikisahkan adalah tentang mencari perubahan dalam lingkungan yang tidak ramah, pergolakan antara diri sendiri dengan dunia luar untuk mencari jalan yang lebih baik.

Kata kunci: Bamiyan Afghanistan, metafora, miniatur, seni lukis, simbol
\end{abstract}

\begin{abstract}
Artworks is one of media for expression and human creative ability in responding to their life experiences. The experience of life, the views and expressions manifested to ideas which are processed into symbols and metaphors into a work of art.

The motive of creation of the works is interest in the beauty of history and culture and the desire to provide more extensive information about Middle Eastern culture and the history of Afghanistan. Prolonged warravaged Afghanistan was once a central part of ancient civilization since it was located in the silk road. The empty hole where the giant Buddha statue in Bamiyan stands is a silent witness to a civilization that has been destroyed by a long war. Ignorance of history produces a fatal behavior. Historical denial means denying the identity of a region so that a nation feels no roots and feels dwarfed. The process of expressing ideas in the form of paintings is realized with miniature characters and artifacts from Afghanistan that are adapted where each figure tells his own story as part of a complex narrative. The stories told are about seeking change in an unfriendly environment, a struggle between oneself and the outside world to find a better way. Keywords: Bamiyan Afghanistan, metaphor, miniature, painting, symbol
\end{abstract}




\section{PENDAHULUAN}

Bamiyan, sebuah provinsi di Afghanistan yang sejak awal abad I adalah lokasi biara Hindu-Buddha dibawah Kekaisaran Kushan. Nama Bamiyan diambil dari bahasa sanskrit, Varmayana, yang artinya The Place of Shining Light. Konon, nama tersebut dipilih karena patung Buddha raksasa di dinding tebing dibuat dengan hiasan batu-batu berharga yang berkilau-kilau bahkan tampak jelas saat malam hari.

Dipercaya sebagai tempat persemayaman orang-orang suci, Bamiyan menjadi pusat agama Buddha di bawah naungan Raja-raja Kushan abad ke-2 dan 3 Masehi. Patung-patung Buddha nan megah itu sendiri diyakini dipahat di tebing-tebing Bamiyan dalam kurun waktu abad ke-3 sampai abad ke-6 Masehi. Catatan sejarah merujuk pada adanya perayaan tahunan yang didatangi banyak peziarah dan adanya sesajian yang diberikan di depan patung-patung itu (Katalog, Museum Nasional Indonesia, hal. 28) Sebelum dihancurkan, patung Salsal Buddha yang artinya Bapa Buddha, di sisi Barat, memiliki tinggi 55 meter, sementara patung Buddha di sisi Timur yang dikenal sebagai Shamama Buddha atau Ibu Buddha, tingginya 38 meter.

Seiring waktu, peradaban berganti dan patung tersebut hanya berupa pahatan batu raksasa tanpa batu-batu berharga yang menghiasi wajah dan tubuhnya. Puncaknya, pada tahun 2001, Taliban, kelompok ekstrimis di Afghanistan, menganggap patung tersebut adalah berhala, walaupun patung tersebut menjadi destinasi wisata yang menguntungkan penduduk sekitar, lalu menghancurkan patung setinggi 55 meter tersebut meninggalkan lubang hampa di dinding tebing yang menjadi saksi bisu jiwa-jiwa yang diliputi kebencian.

Kedatangan Taliban pada tahun 2001 ke Yakawlang, Bamiyan, menimbulkan kekacauan hebat di Provinsi Bamiyan. Mereka membantai sekitar 500 orang dan pada bulan Maret tahun 2001, menghancurkan patung Buddha Bamiyan dan selanjutnya kekacauan demi kekacauan yang melibatkan milisi Taliban terus terjadi. Sementara itu di tahun yang sama, tragedi gedung kembar WTC 11 September terjadi. Tragedi WTC menyebabkan pasukan Amerika, yang menuduh Taliban menyembunyikan pemimpin pembajakan pesawat pada tragedi tersebut, datang ke Afghanistan untuk memburunya (www.bbc.co.uk/newsround/15214375, (diakses pada tanggal 10 Oktober 2018, jam 19.30 WIB). Pesawat tempur Amerika membuat tanda angka delapan di langit sebagai ultimatum dan besoknya bom-bom berjatuhan dari udara tepat di atas markas Taliban bersembunyi. Pada masa itu, anakanak kecil duduk di atap rumah menonton kebakaran gudang senjata Taliban yang berlangsung beberapa hari di gunung. Beberapa gudang senjata yang terbakar mengeluarkan percik-percik kembang api yang terlihat indah di malam hari.

Afghanistan saat ini dikenal sebagai "negara konflik" namun jauh sebelum masa ini, lokasi Afghanistan ada di persimpangan rute perdagangan utama, memiliki sejarah panjang dan rumit. Artefak yang ditemukan di Afghanistan menanggung jejak banyak tradisi, dari Yunani dan Iran ke dunia nomaden Eurasia stepa dan Cina. Misalnya artefak pada zaman Perunggu Baktria, Aï Khanum, Bamiyan, Mes Aynak, Begram, dan Tillya Tepe. Artefak yang ditemukan di situs-situs tersebut memberi penerangan baru telah menghidupkan kembali pembahasan tentang seni, tradisi dan budaya Asia Tengah khususnya Afghanistan.

Afghanistan bukanlah negara ideal sama halnya negara-negara yang lain. Segala sesuatu yang terlihat tidaklah sesederhana penampakannya. Masalah sosial, politik, apa yang diberitakan di media hanyalah sebagian kecil dari penyebab keseluruhannya. Salah satu masalah sosial di Afghanistan yang tidak terekspos di media adalah masalah intoleransi etnis. Jika masalah tersebut dikupas lebih dalam, tokoh-tokoh yang mendalangi berbagai konflik tersebut bukanlah orang yang tidak cukup pendidikan. Konflik-konflik besar 
selalu dilatarbelakangi oleh unsur ekonomi. Namun, jangan lupa bahwa ekonomi tidak akan ada harganya lagi apabila alam ini rusak. Ada satu paradoks dimana kepandaian di satu titik tertentu justru menjadi kebodohan yang akhirnya malah menimbulkan masalah dikemudian hari. Kepandaian menjadi impian banyak orang namun segala sesuatu selalu memiliki dua sisi. Baik atau buruknya tergantung pada pihak manakah kita berada. Bahkan kondisi baik atau buruk ini sangat tidak stabil dan dapat berubah sewaktu-waktu.

Apabila diamati dari berbagai kejadian di sekitar lingkungan masyarakat, akan selalu ditemukan kekelindanan dan pola-pola yang mirip. Tidak ada sesuatu yang berjaya atau bertahan selamalamanya. Masa lalu Afghanistan pernah mengalami masa ketika Kerajaan Kushan berjaya dan Bamiyan yang dilewati jalur sutra menjadi pusat kebudayaan pada masanya. Setelah abad demi abad berganti, Hera menjadi pusat lukisan miniatur dan puisi yang paling berjaya pada masanya hingga kejatuhannya ketika berada di bawah kekuasaan Uzbekistan (Ansari, 2015; hal. 2)

Terdapat satu pola dalam sejarah yang hingga kini terus berulang. Orangorang pandai yang ingin menguasai satu daerah akan berusaha membuat penduduk di daerah itu melupakan kejayaan masa lalunya. Tanpa kenangan akan kejayaan masa lalu, orang-orang hanya akan mengikuti arus dan larut dalam kebiasaan sehari-hari tanpa menyadari potensi yang masih berlimpah di dalam diri mereka. Ada kondisi ketika ketidaktahuan akan sejarah menghasilkan sebuah perilaku yang fatal. Perusakan artefak berarti penyangkalan sejarah, penyangkalan identitas suatu wilayah, dan usaha untuk membuat sebuah bangsa melupakan jati diri serta budayanya sehingga bangsa tersebut merasa tidak memiliki akar dan merasa kerdil.

Kondisi dan kekayaan sejarah Afghanistan di atas menjadi inspirasi dalam menciptakan karya lukis, dengan menghadirkan kembali berbagai fenomena sosial, budaya, politik, spiritual dalam dunia keseharian melalu presentasi simbol-simbol miniatur kedalam lukisan. Ekspresi dan pemikiran yang ingin diungkapkan mencerminkan kondisi yang rumit di negara Afghanistan. Ekspresi yang muncul selalu bersifat ganda. Apa yang ingin diungkapkan tidak semudah ekspresi anak kecil yang menangis ketika sedih dan tertawa ketika senang. Ada konflik pikiran yang terjadi antara berusaha untuk positive thinking sebagai upaya untuk tetap menjaga harapan agar tetap tegar sekaligus rasa putus asa melihat kondisi yang terjadi di depan mata. Harapannya, generasi muda tergugah untuk semakin peduli kepada sejarah budaya bangsa dan negaranya sendiri.

\section{B. Rumusan Penciptaan}

Berdasarkan latar belakang, rumusan penciptaankarya adalah sebagai berikut:

1. Persoalan apa saja yang tepat direpresentasikan secara simbolis melalui objek-objek miniatur dalam lukisan?

2. Bagaimana mewujudkan representasi simbolis objek-objek miniatur dalam lukisan?

\section{Teori dan Metode}

\section{Teori}

Konsep penciptaan karya yang dianggaptepatuntukmenyampaikan situasi Afghanistan adalah dengan story telling (membentangkan bagaimana terjadinya suatu hal (Meity Taqdir Qodratillah, hal. 283). Karakter-karakter bersejarah dan figur-figur sehari-hari di sekitar budaya negara Afghanistan diadaptasi dimana tiap figur menceritakan ceritanya sendiri sebagai bagian dari narasi yang kompleks. Kadang-kadang figur-figur tersebut berubah menjadi metafora, seperti kuda, burung gagak sebagai refleksi pergolakan di dalam diri atau bahaya yang dihadapi sehari-hari. Cerita-cerita yang dikisahkan adalah tentang mencari perubahan dalam lingkungan yang tidak ramah, pergolakan antara diri sendiri dengan dunia luar untuk 
mencari jalan yang lebih baik.

Menurut Dwi Marianto (2017,hal. 3) seni adalah:

Sebagai kata benda abstrak 'seni' adalah kemampuan kreatif manusia dalam menanggapi alam; kemampuan menangani suatu yang menuntut pemecahan masalah; kemampuan istimewa dalam mengubah suatu ide menjadi konsep kreatif yang dinyatakan menjadi suatu yang menarik, fungsional, atau inspiratif.

Tanggapan tentang alam dapat diwujudkan dalam bentuk karya seni rupa yang bertujuan sebagai sarana ekspresi sekaligus menginspirasi. Secara fungsional, karya seni rupa tersebut harus mampu bercerita.

Story telling merupakan seni tertua di dunia, bentuk komunikasi sastra pertama yang disadari (Marie L. Shedlock, 1917: 2) Bukan hal yang tidak biasa melihat kerumunan orang-orang di sudut jalan yang mendengarkan seorang pendongeng dengan narasi sederhana dari sebuah cerita. Orang-orang dari semua budaya telah menggunakan cerita untuk membantu mereka menjelaskan praktik, keyakinan, atau fenomena alam, yang merupakan sarana universal untuk mengomunikasikan tradisi dan nilai-nilai budaya, serta sarana untuk menyampaikan informasi tentang sejarah, ilmu pengetahuan, pemerintahan, dan politik (www.echospace.org/articles/279/ (diakses pada tanggal 14 Desember 2018, jam 01.00 WIB). Story telling itu unik dan merupakan interaksi dinamis antara pencerita dan pendengar.

Unsur yang tidak bisa lepas dari story telling adalah karakter di dalamnya. Secara sadar maupun tidak, karakterkarakter dan simbol yang digunakan tentu tidak akan lepas dari latar belakang penulis yang terimbas dari budaya negara asalnya. Budaya terdiri dari pola, eksplisit dan implisit, dari dan untuk perilaku yang diperoleh dan ditransmisikan oleh simbol. Merupakan pencapaian khas dari kelompok manusia, termasuk perwujudan mereka dalam artefak; inti penting dari budaya terdiri dari ide-ide tradisional (N. Adler, 1997; hal. 14)

Dari sudut pandang semiotik, artefak berarti "benda" yang tidak mudah diidentifikasi dan dikenali, secara arkeologis, "sesuatu" yang dibuat oleh orang di masa lalu dan ditemukan oleh arkeolog (François Djindjian, 2000, hal. 3) Budaya kuno Afghanistan berdasarkan artefak yang ditemukan di Afghanistan yang paling terkenal adalah artefak-artefak Buddha dan lukisan miniatur. Pada abad $\mathrm{XV}$, gaya lukisan miniatur Herat, Barat Afghanistan, mulai berkembang di bawah pemerintahan Timur. Hal ini terungkap dari penemuan dokumen tahun 1410, dan berakhir pada 1507 saat pemerintahan Shaibari Khan.

Kelompok ini didirikan oleh anak lelaki Timur, Shah Rokh, dan mencapai kejayaannya di bawah kepemimpinan anak lelaki Shah Rokh, Baysungur Mirza (meninggal 1433). Pada masa itu, Herat melahirkan seniman-seniman yang menyebar ke seluru pelosok Persia dan Afghanistan. Kelompok ini berakhir pada 1503 saat Herat dikuasai Uzbek. Perkembangan kehidupan kota dan budaya feodal Herat menciptakan kebutuhan yang membuat seni miniatur berkembang. Tulisan-tulisan berada dalam harmoni dengan lukisan monumental dan seni terapan dalam desain naskah yang indah. Dalam miniatur Herat, banyak figur yang muncul di tempat yang bervariasi, bertumpuk satu sama lain dan elemen yang sedemikian rupa sehingga menciptakan efek yang satu muncul di belakang yang lain. Penciptaan lukisan miniatur Herat yang paling terinspirasi dari kisah-kisah kepahlawanan, perjuangan, percintaan, spiritualitas, peperangan, pengadilan, dan kondisi sosial, ekonomi, politik yang tercermin pada kehidupan sehari-hari pada masa itu namun kebanyakan berasal dari sastra dan puisi.

Sastra adalah bahasa (kata-kata, gaya bahasa) yang dipakai di kitabkitab (bukan bahasa sehari-hari) (Meity Taqdir Qodratillah, hal. 1249). Salah satu 
contoh karya sastra adalah puisi, Puisi adalah segala jenis bahasa verbal atau tulisan yang terstruktur berirama dan dimaksudkan untuk menceritakan suatu kisah, atau mengekspresikan segala jenis emosi, ide, atau keadaan (Bernie Ollila \& Joe Jantas, 2006; hal. 1). Puisi digunakan untuk mencapai ekspresi artistik ini dalam beberapa cara. Ada bentuk dan pola tertentu yang diikuti penyair dalam proses komposisi pekerjaan mereka. Bentukbentuk yang berbeda ini lahir dari gerakan seni dan budaya yang terpisah, yang paling populer dari bentuk-bentuk ini adalah elegi, naratif, ode, balada, soneta, villanelle,

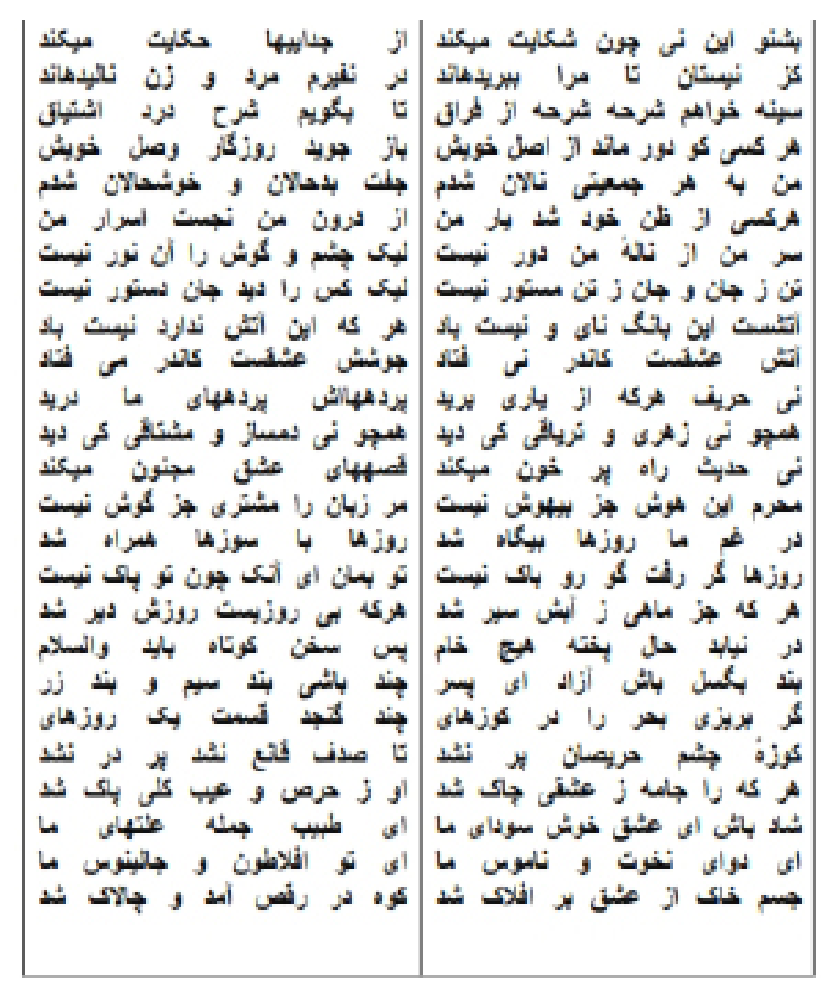

Gambar 1. Contoh puisi Persia karya Jallaludin Rumi

Terjemahan puisi di atas dalam bahasa inggris:

Listen to this reed how it complains, telling a tale of separations.

Saying, "Ever since I was parted from the reed-bed, man and woman have moaned in (unison with) my lament.

I want a bosom torn by severance, that I may unfold (to such a one) the pain of love-desire.
Every one who is left far from his source wishes back the time when he was united with it.

In every company I uttered my wailful notes, I consorted with the unhappy and with them that rejoice.

Every one became my friend from his own opinion; none sought out my secrets from within me.

My secret is not far from my plaint, but ear and eye lack the light

(whereby it should be apprehended).

Body is not veiled from soul, nor soul from body, yet none is permitted to see the soul.

This noise of the reed is fire, it is not wind: whoso hath not this fire, may he be naught! 'Tis the fire of Love that is in the reed, 'tis the fervour of Love that is in the wine.

The reed is the comrade of every one who has been parted from a friend: its strains pierced our hearts.

Who ever saw a poison and antidote like the reed? Who ever saw a sympathiser and a longing lover like the reed?

The reed tells of the Way full of blood and recounts stories of the passion of Majnun.

Only to the senseless is this sense confided: the tongue hath no customer save the ear.

In our woe the days (of life) have become untimely: our days travel hand in hand with burning griefs.

If our days are gone, let them go!-'tis no matter. Do Thou remain, for none is holy as Thou art!

Except the fish, everyone becomes sated with water; whoever is without daily bread finds the day long.

None that is raw understands the state of the ripe: therefore my words must be brief. Farewell!

$O$ son, burst thy chains and be free! How long wilt thou be a bondsman to silver and gold?

If thou pour the sea into a pitcher, how much will it hold? One day's store. The pitcher, the eye of the covetous, never becomes full: the oyster-shell is not filled with pearls until it is contented.

He (alone) whose garment is rent by a (mighty) love is purged entirely of covetousness and defect. 
Hail, our sweet-thoughted Love - thou that art the physician of all our ills,

The remedy of our pride and vainglory, our Plato and our Galen!

Through Love the earthly body soared to the skies: the mountain began to dance and became nimble (The Mathnawî̀-yé Ma 'nawî,, 1926; hal 1)

Representasi yang dimaksudkan dalam tulisan ini adalah suatu cara untuk menyajikan relasi antara pengalaman hasil observasi dalam pikiran dengan objek atau simbol yang mana objek dan simbol tersebut kemudian disajikan dalam bentuk karya lukis. Pengalaman dalam pikiran yang tadinya bersifat abstrak dan tidak tertata diendapkan dan disusun membentuk sebuah cerita, dituangkan dalam karya berupa objek dan simbolsimbol yang mampu merepresentasikan pengalaman tersebut.

Simbol yang digambarkan pada objek memungkinkan kita untuk memecahkan beberapa makna di belakangnya dan memahami budaya. Simbol adalah segala sesuatu yang mewakili, atau mewakili, sesuatu yang lain (www.britishmuseum.org (diakses pada tanggal 14 Desember 2018, jam 01.30 WIB). Dalam sebuah cerita, karakter, tindakan, objek, atau binatang dapat menjadi simbol. Seringkali simbolsimbol ini mewakili sesuatu yang abstrak, seperti kekuatan alam, kondisi dunia, atau ide. Motivasi dibalik penggunaan simbol bervariasi untuk memaksakan kekuasaan, untuk menegaskan posisi, untuk melindungi pemakainya atau untuk mengidentifikasi seseorang dengan keluarga atau komunitas. Di mana tidak semua anggota masyarakat melek huruf, simbol sangat penting dalam mengkomunikasikan ide atau afinitas. Koneksi dengan leluhur, silsilah masa lalu, klan, keluarga dan sejarah leluhur adalah identitas pribadi yang signifikan dan ini sering dikodekan dalam simbol yang diwariskan dari satu generasi ke generasi lain.

Selain simbol, figur-figur metaphor juga menjadi bagian darikonsep penciptaan. Metafora secara tradisional telah ditafsirkan sebagai fenomena linguistik, sebagai sesuatu yang diproduksi dan dipahami oleh penutur bahasa alami. Berbeda dengan simbol yang berkaitan dengan budaya, metafora bersifat personal sesuai dengan pengalaman dan pemahaman individu.

Seringkali tidak disadari makna sesungguhnya dari satu kejadian yang terjadi saat itu dan baru menyadari maknanya setelah kejadian demi kejadian berikutnya menyusul. Ada berbagai perasaan dan pemikiran yang muncul secara alami pada proses tersebut namun bagi penulis perasaan dan pemikiran tersebut tidak bisa diungkapkan secara gamblang mengingat kondisi sosial politik di negara asal. Perasaan dan pemikiran yang seringkali tidak bisa diungkapkan secara spontan tersebut diendapkan terlebih dahulu hingga menjadi kenangan dan pengalaman lalu diungkapkan dengan objek-objek simbolis dan metafora dalam lukisan.

Rasa batin yang muncul termanifestasikan dalam bentuk-bentuk abstrak lelehan tinta dan goresan-goresan spontan. Kenangan, pengalaman dan cerita-cerita yang ingin diungkapkan dilukiskan dalam berbagai simbolis, metafor yang kental dengan budaya Afghanistan.

\section{Metode}

Metode untuk memvisualisasikan ide yang ingin diungkapkan ke dalam karya ini adalah:

1. Teknik Wet on Wet, yaitu pengaplikasian cat air maupun tinta dilakukan saat kertas dalam keadaan basah.

2. Teknik Arsir atau dalam istilah lukisan miniatur disebut ring-ring. Kekhasan teknik ring-ring ini adalah pengarsiran diaplikasikan dengan kuas khusus yang sangat kecil untuk menciptakan garis-garis arsiran yang sangat halus dan kecil.

3. Teknik Wash, yaitu teknik dalam penggunaan cat air dengan menggunakan banyak air agar warna bisa rata. Teknik wash pada karya bisa dilakukan berulangulang setelah layer sebelumnya kering untuk mencapai warna yang diinginkan. 
Proses pembentukan karya seni melalui beberapa tahap dimana tiap seniman memiliki cara yang berbeda-beda. Tahap perwujudan berawal dari gagasan atau ide dalam pikiran yang kemudian divisualisasikan ke dalam karya. Secara garis besar, tahapan pembentukan karya ini terbagi dalam:

\section{Persiapan}

Dalam tahap persiapan, kertas samson dipotong menggunakan cutter sesuai ukuran lukisan yang diinginkan, lalu direndam dalam air selama satu minggu lalu sebagian dikeringkan. Tinta cina, air, botol spray yang sudah diisi air, dan kuas disiapkan di area yang akan digunakan untuk pembuatan karya.

\section{Pengeraman (Incubation)}

Untuk menemukan mood yang tepat, musik yang sedang disukai diputar dalam volume keras. Membaca buku-buku berilustrasi, buku sejarah, atau menonton film berbagai genre termasuk film dokumenter dilakukan untuk pengeraman ide. Ide-ide yang muncul seringkali bertumpuk satu sama lain yang lalu dijernihkan agar ide lebih terarah dengan mengikuti kegiatankegiatan meditasi.

\section{Inspirasi}

Dalam proses inspirasi ini, kertas yang sudah kering, setengah kering, dan masih basah dijajarkan lalu tinta cina digoreskan dengan menggunakan kuas. Goresan yang terbentuk kadang berasal dari imaji landscape alam, kadang berupa garis-garis atau percikan acak.

\section{Pemunculan}

Setelah melewati proses perenungan, pematangan ide, dan pembuatan garis besar karya dengan goresan tinta, karya ditunggu hingga benar-benar kering. Sketsa-sketsa objek miniatur mulai dibuat diwarnai dengan cat air, dan diberi detail garis-garis yang sangat lembut sehingga sketsa hanya membentuk siluet saja. Gom arab berfungsi sebagai lem yang dioleskan pada bagian-bagian tertentu yang ingin ditutup dengan emas prada, silver atau cooper leaf. Setelah karya selesai, fixative disemprotkan melapisi seluruh permukaan karya.

\section{PEMBAHASAN KARYA}

Karya "Why Abstain" terinspirasi oleh keindahan Candi Sewu. Candi Sewu berusia lebih tua daripada Candi Borobudur sekaligus kompleks candi terbesar kedua setelah Borobudur. Candi Sewu yang merupakan Candi Buddha berdampingan dengan Candi Prambanan yang kemungkinan sebelumnya Candi Buddha namun kemudian dialih fungsikan menjadi Candi Hindu. Dua patung Dharmapala duduk tegap menjaga candi dengan posisi saling berhadapan dalam sunyi.

Abstain berarti tidak memberikan suara atau menjauhkan diri. Di sisi kanan karya adalah siluet Candi Sewu dengan dua patung Dharmapala atau penjaga Dharma yang saling berhadapan. Di tengah langit ada kaligrafi Persia yang artinya, kejujuran secara alami adalah inti kehormatan manusia yang sangat berharga sekaligus tidak semua orang memilikinya. Kaligrafi tersebut tepat di tengah persimpangan dua spiral yang digambar dengan teliti menggunakan prinsip golden proportion. Di tengah masing-masing spiral ada Candi dengan Dharmapala yang setia menjaga candi, serta seekor kuda yang sedang

Why Abstain menantang mana yang akan dipilih apakah kesetiaan seperti dua patung Dharmapala atau kuda yang setia membantu manusia atau sama sekali tidak bersuara dan tidak menjadi bagian dari halhal yang membuat manusia boleh disebut sebagai manusia.

Karya yang berjudul Forbidden bercerita tentang emas, mineral, tambang dan kekayaan alam lainnya selalu diincar oleh orang-orang yang memiliki kepentingan. Beberapa orang berniat untuk memperkaya dirinya sendiri dan sedikit yang berniat untuk membantu orang lain. Berbagai macam motivasi untuk menguasai kekayaan alam ini membawa konflik-konflik yang rumit dan tidak ada habisnya. Orangorang yang tidak memiliki kekuasaan nasibnya akan selalu terombang-ambing di tengah konflik. Mereka berjuang untuk bertahan hidup dan tidak kehilangan harapan berjuang untuk masa depannya di 


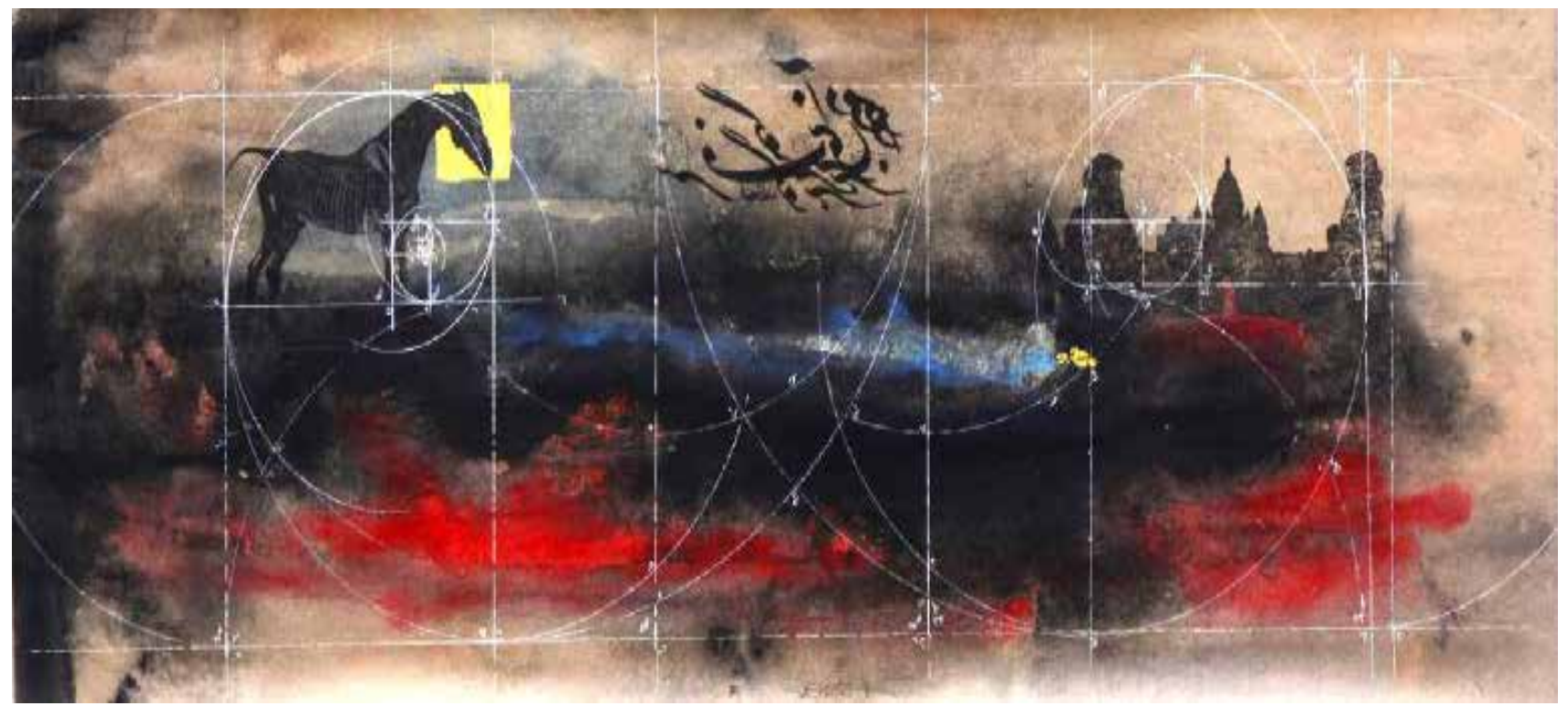

Gambar 2. "Why Abstain" Tinta, cat air, gold dan silver pada kertas, $45 \mathrm{~cm}$ x $120 \mathrm{~cm}, 2018$ (Foto: Amin Batoory, 2018)

tengah perebutan kekuasaan yang sudah terlalu rumit.

Forbidden menggambarkan kudakuda yang sedang berlari melintasi padang gurun yang luas namun dihadang oleh berbagai rintangan bom yang jatuh dari langit dan tank yang siap dengan senjatanya mengarah ke mereka. Kudakuda tersebut berlari di atas tanah yang di bawahnya mengandung emas. Ada sebuah pepatah kuno mengatakan, prajurit muda meninggal karena impian seorang tua.
Karya ini menceritakan situasi ketika orang-orang yang tidak memiliki kekuasaan terus berusaha untuk memperjuangkan kebebasannya dan akan selalu ada orang atau hal-hal yang menghalangi apa yang ingin dicapai. Simbol Buddha yang berada di tengah menceritakan bahwa untuk mencapai satu titik kebahagiaan, kudakuda tersebut harus tepat ada di tengahtengah tidak terlalu mundur pada jurang di belakangnya atau terlalu jauh ke tebing curam di depannya. Ada saatnya berbicara ada saatnya saat kondisi tidak memungkinkan untuk diam.

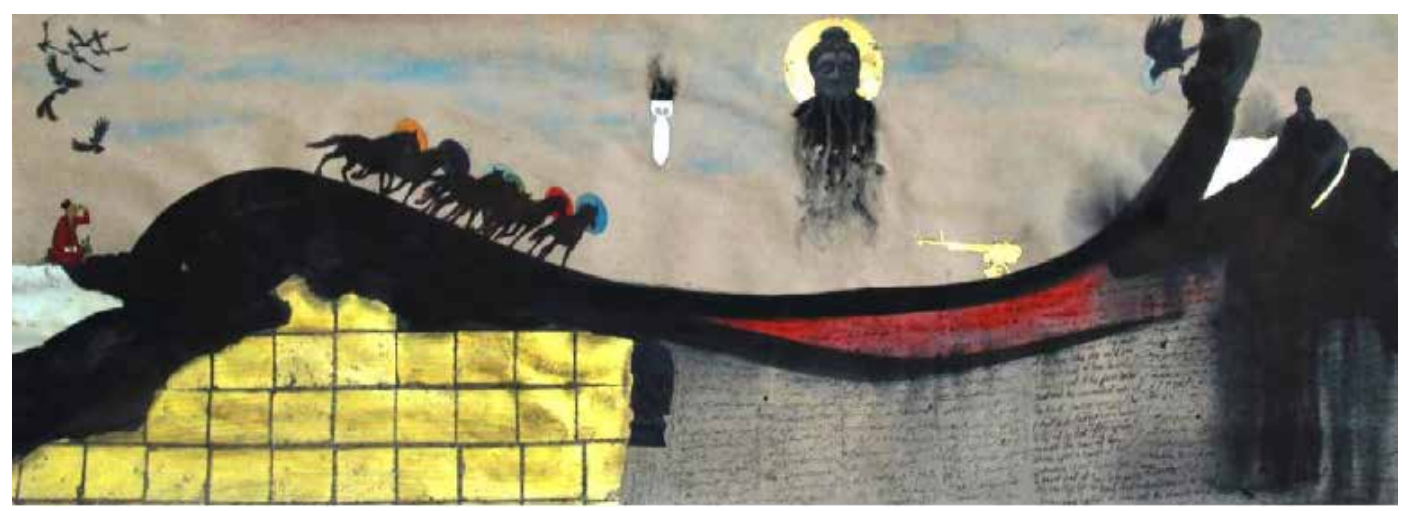

Gambar 2. "Forbidden" Tinta, cat air, gold dan silver pada kertas, 45 cm x 120 cm, 2018 (Foto: Amin Batoory, 2018) 


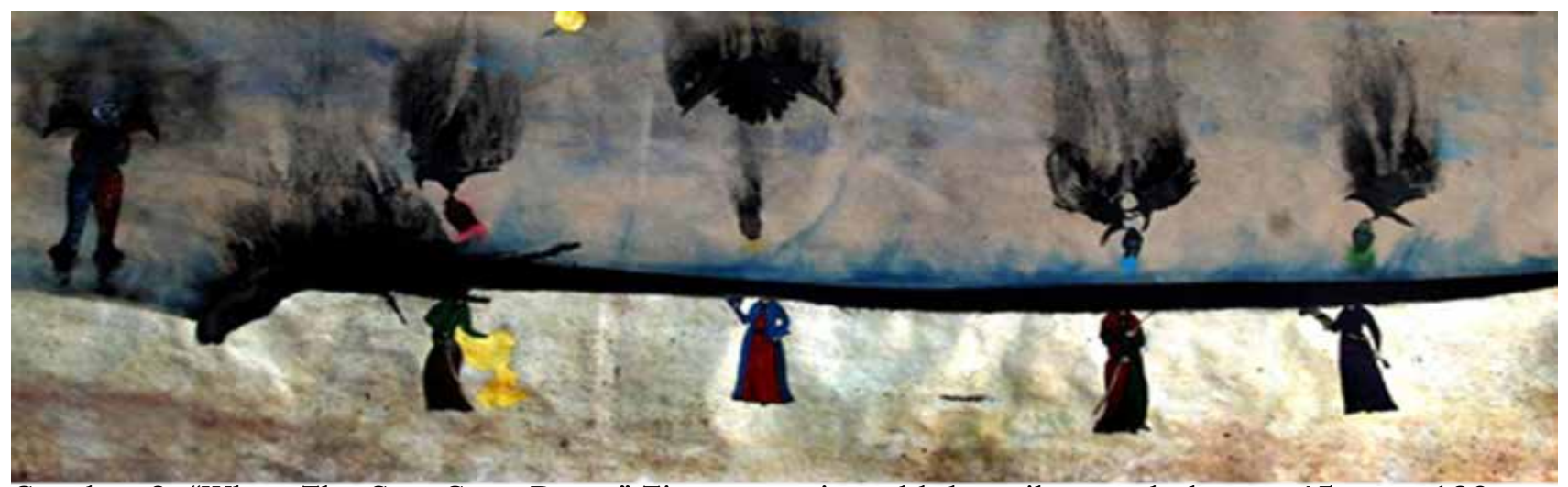

Gambar 3. "When The Sun Goes Down" Tinta, cat air, gold dan silver pada kertas, $45 \mathrm{~cm} \times 120 \mathrm{~cm}$, 2018 (Foto: Amin Batoory, 2018)

Karya When The Sun Goes Down menceritakan pendapat seniman tentang para penguasa yang terlibat dalam terjadinya konflik. Para penguasa ini adalah orang-orang yang memiliki potensi untuk membantu sebuah negara sekaligus menghancurkan satu negara. Sebagai mahasiswa atau pebisnis kelas menengah mungkin pergi ke pantai atau membeli telepon genggam yang tak lebih dari lima juta rupiah sudah menjadi kesenangan tersendiri namun orang-orang yang terlibat dalam terjadinya konflik seperti memiliki dunia yang berbeda dengan orang pada umumnya. Kebanyakan orang merasa bersalah ketika menyakiti perasaan orang lain dengan kata-kata namun bagi para penguasa ini pertimbangan mereka adalah mana yang bisa dikorbankan untuk mencapai tujuan yang diinginkan dan bisa saja yang dikorbankan adalah sejumlah nyawa.

Figur-figur manusia dalam karya tenggelam dalam lautan perak dan kepalakepala yang merupakan kesadaran dan akalnya dibawa oleh burung-burung gagak. Sosok manusia bersayap kecil dengan bentuk deformatif mengamati di sisi kiri masih menimbang-nimbang apa yang harus ia perbuat. Ketika matahari terbenam, malam menyelimuti dan membuat bumi ini berubah seperti berada di dunia lain melambangkan para penguasa yang hidup dalam level berbeda daripada orang awam. Manusia memiliki potensi-potensi tak terhingga dari kesadaran Illahinya namunbanyak orang-orang pintar yang akan mencabut kesadaran ini agar manusia terus terjebak dalam ketakutanketakutan akan keterbatasan yang bersifat duniawi. Di sebelah kiri ada sosok manusia dengan sayap yang sedang tumbuh yang membuatnya bisa menjadi apa saja. Apakah ia akan menjadi malaikat penolong, menjadi gagak atau menjadi manusia tanpa sayap. Sosok manusia bersayap kecil yang mungkin bias menjadi gagak ini metafora dari orang yang berusaha menolong tapi malah memperburuk situasi.

\section{SIMPULAN}

Proses dalam mewujudkan sebuah karya merupakan tahapan yang panjang yang berawal dari pemikiran mentah yang masih meloncat kesana kemari. Pemikiran tersebut kemudian diendapkan dalam proses inkubasi. Proses inkubasibisaberupa membaca referensi untuk menambah pengetahuan, diskusi untuk mematangkan ide atau meditasi untuk melihat persoalan dengan lebih jernih. Pengalaman hidup, pandangan-pandangan dan ekspresi yang muncul tersebut menjadi ide dan gagasan yang kemudian diolah menjadi simbolsimbol dan metafora, diwujudkan menjadi sebuah karya seni yang mampu bercerita kepada penikmatnya.

Seperti yang telah diuraikan sebelumnya, karya seni merupakan salah satu media untuk berekspresi serta kemampuan kreatif manusia dalam menanggapi pengalaman hidupnya. Tiap seniman dengan pengalaman hidupnya 
yang berbeda menciptakan ciri khas dalam karya yang diciptakan yang merupakan cerminan jiwanya. Metafora dan simbolsimbol dalam karya seni memunculkan kebebasan untuk seniman berekspresi dan kebebasan bagi penikmat seni untuk menginterpretasikan karya sesuai pengalaman hidupnya masing-masing.

Pengalaman sebagai saksi atas fenomena sosial budaya, politik, dan spiritual yang terjadi dalam keseharian yang kompleks memberikan pandangan baru dan pelajaran yang berharga dalam menjalani kehidupan. Melalui karya lukis ini, pengalaman, pandangan dan budaya Afghanistan diperkenalkan kepada masyarakat penikmat seni. Harapanharapan terus tumbuh selama proses penciptaan karya ini agar kesadaran generasi muda untuk menjaga dan mengetahui sejarahnya. Dengan belajar dari masa lalu, diharapkan apa yang sudah berjalan dengan baik tetap bertahan dan apapun yang sedang mengalami penurunan menuju kondisi yang tidak baik dapat segera dicegah.

Penciptaan karya muncul karena adanya ketertarikan terhadap keindahan sejarah dan budaya serta keinginan untuk memberikan informasi yang lebih luas tentang kebudayaan Timur Tengah dan sejarah Afghanistan. Kondisi Afghanistan saat ini mungkin tidak dapat memberikan cukup informasi kepada masyarakat bahwa sebelumnya Afghanistan khususnya Bamiyan pernah menjadi pusat kebudayaan karena letaknya yang dilewati jalur sutra. Simbol-simbol yang berkaitan dengan budaya dan sejarah Afghanistan menjadi unsur dalam lukisan untuk berekspresi dan menyampaikan cerita-cerita tentang Afghanistan serta pesan-pesan yang ingin disampaikan.

Proses mengekspresikan gagasan kedalam wujud karya lukis diwujudkan dengan karakter-karakter miniatur dan artefak-artefak dari Afghanistan yang diadaptasi dimana tiap figur menceritakan ceritanya sendiri sebagai bagian dari narasi yang kompleks. Cerita-cerita yang dikisahkan adalah tentang mencari perubahan dalam lingkungan yang tidak ramah, pergolakan serta kegelisahan di dalam diri sendiri dengan dunia luar untuk mencari jalan yang lebih baik.

Dalam proses pembuatan karya, banyak hal yang didapatkan dan dirasakan. Figur-figur artefak yang menarik untuk dimasukkan dalam lukisan mendorong untuk membaca lebih dalam tentang sejarah dan cerita di dalamnya. Lukisan miniatur diwujudkan untuk mengilustrasikan satu narasi sehingga tiap figurnya selalu nampak sedang melakukan sesuatu. Begitu pula artefak Buddha dan posisinya memiliki maknanya sendiri. Dari makna dan kegiatan yang sedang dilakukan simbol-simbol tersebut kemudian digabungkan menjadi sebuah karya yang menceritakan pengalaman dan pemikiran yang ingin disampaikan. menumbuhkan rasa keingin tahuan dan kemauan untuk mempelajari sejarah dan berpikir lebih kritis agar tindakan-tindakan yang dilakukan mampu memberikan manfaat bagi dirinya sendiri dan orang lain. Semoga karya-karya ini mampu membuka wawasan akan budaya Timur Tengah dan memperkaya dunia seni lukis di Indonesia.

\section{KEPUSTAKAAN}

Buku:

Adler, N, 1997. International Dimensions

of Organizational Behavior. Ohio: South Western College Publishing Djindjian, François, 2000. Artefact Analysis. France: Université de Paris: 1-PanthéonSorbonne, Paris

Maryanto, M. Dwi. 2017. Art \& Life Force in a $Q u a n t u m$ Perspective, Yogyakarta: $\mathrm{S}$ c rit to Books Publisher

Shedlock, Marie L., 1917. The Art Of The Story Teller. New York: Appleton \& Company

Kamus:

Qodratillah, Meity Taqdir. 2008. Kamus Bahasa Indonesia. Jakarta: Pusat Bahasa. 
Katalog:

UNESCO, 2016. Simpang Budaya: Bamiyan

$\&$ Borobudur. Katalog, Museum

Nasional Indonesia. 8-28

Desember

Diktat:

The Mathnawî-yé Ma`nawî. [Rhymed

Couplets of Deep Spiritual Meaning]

of Jalaluddin Rumi. Translated

from the Persian by Ibrahim

Gamard (with gratitude

for R. A. Nicholson's 1926 British t ranslation).

Jurnal:

Ansari, Maria, Farjad Faiz dan Amna

Ansari. 2015. History of Persian

Miniature Painting through Herat

School of Miniature. International

Journal of Scientific and

Research Publications.

Volume 5.

Ollila, Bernie, Joe Jantas, The Definition of Poetry 15 Desember, 2006. 